\title{
The Negative Effect of Pension Fund and the Steps to Resolve the Situation in Albania
}

\author{
PhD. Candidate Gilda Bajrami \\ Lecturer at "A.Xhuvani" University, Faculty of Economics, Faculty of Economics, Elbasan \\ Email: gildabajrami@yahoo.it
}

Doi:10.5901/ajis.2014.v3n3p451

\begin{abstract}
Pension system provides a financial support towards elder people as well as those that are incapable to work, by assuring the main providers regarding to the consumer balancing tools through all the life cycle. For the majority of population, the pension benefits present the main income stream during the retirement time. Each country does have a national strategy seeking the social insurance provided for all the people, thus expressing the society solidarity for groups in needs due to the health problems, old generation problems or unemployment. By social protection through the re-distribution of incomes, social welfare is provided. Nowadays the pension fund management presents a very important topic in the sphere of economics. The aim of this paper is to examine the negative impact of pension found on Albania pension system. The paper argues about the problems that pension found are facing in Albania and the measurements that have to be taken in order to have a more efficient pension fund management. The methodology used in the preparation of this paper will be that of the utilizing the foreign and national literature.
\end{abstract}

Keywords: Pension fund, the contribute, the benefits, incapable

\section{Introduction}

The $21^{\text {st }}$ century has faced up humanity with many great human challenges. One of these actual sharpest problems is the preservation of the human resources development equilibrium.

We are in front of the fact that the rhythm of birth are decreasing and the average life -length of people is increasing, the third age group number is raising at a very galloping rhythm compared to the working power. At such conditions, the old system of social insurance Pay-As-You-Go, ideated over 100 years ago, whose at its basis stands the principle of solidarity and generations' continuity, each day is approaching the impossibility to fulfill the needs of the third age population. If there would be an unchanging world the principle of Pay-As-You-Go financial system, it would be more stable if the appropriate tax fee is decided as well as the right norms of benefit. But the world is going forward globalization, opposite the effects of economic decline, unemployment, the early retirement and the increase of the average life-length, the increase of the expectancy on the inflation norm and the incredible increase of the human services' costs.

With an aging population and together with the burden of pensions and social welfare, the economic growth will always be very little. If there is no measure taken today, it is going to be very difficult. ${ }^{1}$

The main reason of the reformation of social insurance system requires is connected to actual problems that worry our economy. The system does not offer financial stability. This instability is directly connected to other factors as well. The transition from the economic plan in that of the market was accompanied by negative impacts, such as massive increase of unemployment, increase of informal economy, and the early retirement. These changes led to the deterioration of the contributor/benefiter ratio, which from the value of 4 contributors per benefiter decreased into 1.3 contributors per 1 benefiter. The participation of the contributors into this scheme is relatively low. The process of privatization of the strategic sectors of economy will influence in the increase of the private sector role in economy. This will as well lead to the increase of invasion in the scheme. The demographic prognosis testifies that in Albania it will raise the undesired tendency of the population's aging. Having an increase of this category of population, therefore, we will have an increase of expenditure in the scheme of Social Insurance. The setting of minimum and maximum limits in the amount of pension, in combination with the unequal verified indexing during the increase of the pensions have influenced in the weakening of dependence between the given contributions and the benefits that can be profited by the pension's scheme.

\footnotetext{
${ }^{1}$ Martins Kazaks, kryeekonomist Swedbank ne Riga
} 


\section{Actual Problems of the Pension System}

There is need to stress the fact that pensions are an indispensable and important element of social protection. 17.2 per cent of the population benefits from them, an indicator that has a clear tendency towards increase. It is spent 40.2 billion of Albanian Leks from the social insurance

It exists a low level of incomes in ratio to the GNP of 5.03 per cent vs. 8-10 per cent of the countries surrounding us, a low benefiter-contributor ratio of 1.3 and 1, a very low scale of replacement (the ratio of average pension to average salary) of 38-42 per cent, a low percentage of the working population inducted in the system of only 30-32 per cent, etc. ${ }^{2}$ All these elements have significantly affected the budget financing and subventions. The system offers low benefits with high contributions and the strategy of its reformation and increase of its financial stability is connected to these main issues that require solution.

As well, the formula of benefit for the pension is the basis of the pension plus 1 per cent per working year. But the only benefiters to benefit the additional amount set by the law in such cases are those individuals whose salary is much higher than a minimum salary. Theoretically, this would insure 73 per cent of the salary for a person of average salary that would result to be satisfactory for the individual. But in reality the average full pension in the urban sector according to the official data reaches $40-48$ per cent of the gross covered salary, which means that it does not differ a lot from the basic pension.

First, this pension is limited at the double of the basic pension, where the individuals with higher incomes who can assure incomes higher than the average salary will reach the limits.

Second, the pension is limited in case an individual reaches 75 per cent of the average net salary higher than that of the three consequent last years in the final 10 years.

Third, the pensions are limited even more because the law previews that the salaries in the past should be reevaluated in accordance to the increase of contributions per year, whereas the limits in practice are applied on the average of normal salaries. The norms of replacement for the salaries which are higher and bearing difficulty result at the rate of 30-35 per cent. Based on the formula of pension calculation, it is noticed that the redistribution is applied only in the cases when the pensioner has paid the minimum contributions per month due to his/her minimum salary.

Another element of this formula is the coefficient of the contribution period. The coefficient is important for the individuals who have not contributed for 35 years despite they have had a high salary. It can happen that someone has paid maximum contributions for 25 years, contributing more in the scheme rather than a person of 35 years of contribution and with a minimum salary. There are no benefits even for individuals who have contributed for more than 35 years, even though they pay minimum contributions.

Pensions have to be indexed according to inflation. But in reality it has been done only an increase of the minimum pensions higher than compared to the average and maximum pensions. The real average pension is supposed to be under the average standard of living, the individuals benefit minimum pension despite the amount of contributions contributed in the scheme. The international data demonstrate that for every increase of 0.3 per cent of employment we have got a reduction of 1 per cent of the norm of contributions in the scheme. Thus, with the decrease of the contribution norms with 7-9 per cent, employment should raise with 10 per cent. In this way, there will be generated more incomes in the scheme of social insurance.

Not offering stimulus in the formula of benefits for the individuals who contribute, it makes it impossible the declaration of the real salary of individuals. When the pensioners profit a minimum pension despite the fact of declaration in minimum salaries, it is normal that they choose to declare the minimum salary. This situation is very real in the private sector, whereas about 50 per cent of the employees declare minimum salary when this sector offers higher salaries than the state sector. This is because the maximum salary that is subject of contributions equals 5 times of the minimum salary, whereas the maximum pension they benefit is twice the minimum pension,

It exists a disproportion at very high levels. The individuals with high incomes will benefit a maximum pension quicker than the fulfillment of the 35 years of working contribution.

For these individuals, early retirement, despite the lowering percentages that is applied, does not affect negatively because the pension does not change. In this way the limits put for the payment of the pensions serve for the preservation under control of the expanses for the pensions but on the other side they provide the individual a stimulus to early retirement.

An over-favoring is attributed to the pensioners in the rural sector, where the employees in this sector are estimated with fixed contributions and the calculation of the contribution is done on basis of the minimum urban salary

$2 \mathrm{http}: / /$ int/com 
and he/ she pays to the ISSH (Institute of Social Insurance) the difference between this value and the fixed contribution that is paid by rural employees. Rural contributors are more namely contributors than valuable ones. The average contribution of the rural contributors is $1 / 3$ of the urban area's contributions. The minimum pension of rural pensioners is about 68 per cent of the urban areas' pensioners. In fact, the rural old age pension is more a social help for the selfemployed in the agricultural sector and it is based on the low contributions they pay. The process of equalizing the rural pensions to the urban ones remains an actual problem that exists in the system of pensions.

\section{The Importance of the Pension Scheme Reformation}

All these changes sensitively affect the system creating the imposibility for financing. In order to resolve this problematic situation, it is important the undertaking of a general reform of pensions. At its foundations, it stands the construction of an altered system of multycolumns which would make possible the combination for financial participationin the pension fund of the old state system P.A.Y.G to the private system of the individual's responsibility to take part in the solution of the social problems. This system would be composed of the column of the state system P.A.Y.G, the second column is the mandatory private system, the third column is the suplementary voluntary private system. Pensions' reforms have occurred in all the member states of EU. A strong tendency of this reformationas been the speed of mix columns spread in these countries.

Some states have implemented an imaginary estimation. The estimations consider GNP in increase and the future of lifelength to define the benefits.

The consolidation of the scheme with three columns in Albania will be a very productive inititive. Borrowing form the model of the EU member states, it will be reached to create a system of pensions based on the self- interet and responsibility to be insured at third age.

Latvia $^{3}$ is the best example for the existence of the best effective and progressive pension system. According to this reform we will have:

1. The mandatory non-financed pension plan, well-known as P.A.Y.G. is a plan that has at its basis the collection of the taxes to govern the third age which is transfered in the social budget and it is used to finance the actual generation of pensioners.

2. The state mandatory voluntary pension plan.

A part of the paid funds at the first level of the pension system is divided in order to give the pensioners the opportunity to be invested at benefit and to increase the old age of pensioners. Choosing the fund manager and the most appropriate investment plan where there are invested means in the financial markets, se secure the pensions' increase. The people who are involved int his scheme born after July 1. 1971.

With the increase of the pension's age it can be chosen to add the estimated capital in the second levelof the pensions' system at level 1 to receive pension from the state to buy the policy of ensuring the life of the pensioner by insurance companies and to benefit a pension according to the terms of concesion. The total of contributions of social insurance for a pension are divided between the pension systems of level 1 and 2. You ar enot obliged to pay any additional tax of social contribution for participation at column 2 . In the future the assets assured in pension system number 2 together with the additional benefit can compose a considerable contribution of the pension.

3. The pivate pension fund gives the opportunity to gather the voluntary savings for a private pension to complete pension 1,2 . The investments in private pensions can be done by the individual in his/her means, by the employer in the account of his/her imployee by the company funds. Different by the state pensions, the accumulation of the private pensions can be reached at the age of 55 and it is iheritable.

Each person who is insured at the age of 65 benefits an amount of pension 80 per cent of the average of his/her entire life incomes after having paid contributions for 45 years. The scheme will allow people themselves to define their pension age, if one person born after January 1. 1955 and he has paid contributions up to 37.5 years, he/she (for women this system will be relevant only after 2028) can retire between 62-65 years old.

If the person remains at work until the age of 68 , there will be applied special bonuses. Exactly, this gives value to the system because in reality currently pensioners are paid a maximum pension that is double the minimum pension even when he has fulfilled and overpassed the years to benefit pension.

The EU member states specifically, the example of Denmark ${ }^{4}$ the situation of the employees as far as it concerns

\footnotetext{
3 Pension system in the UE contingent liabilities \& assets in public and private sector.

${ }^{4}$ Pension system in EU contingent liabilities \& assets in public and private sector
} 
the employees who are 50 years old are praised for their experience and performance at work. Very few european countries have a great ratio of the old people still working compared to Denmark, where about 58 per cent of the 55-64 year old are still working. The retirement age is 67 in Denmark, the pensions' benefits cannot be paid before the age of 60. The Danish government pays an essential importance to the treatment done to the integration of the old employees at work. It is spent about 7.4 per cent of the GNP for the treatment and education. Many courses and programs are specified for the population of over 50 years old.

Meanwhile Swenden ${ }^{5}$ as well decided that the personal accounts were the best current way to insure the workers who can benefit a secure and apppropriate pension. Thus, there were two solutions before: to increase the tax or to lower the benefit of the ability paying lengthening or to give to the workers a private pension account. It was decided that privatization was the most adequate way. The new system has got four main features.

1. Partial privatization. Workers can invest 2.5 points of per cent at the 18.5 per cent of their incomes that they have to leave aside to retire. Workers can decide very quickly at what fund they should send their savings.

2. Imaginary accounts. The taxes of the remaining salary finances the dramatic structuring of the governing PAYG program. Instead of paying benefits on basis of the working force years, the new system previews a pension based on the amounts of the tax obligation (taxes) which the worker has paid in the system.

3. Net insurance to protect the poor. The state is going to insure a minimum pension fund insured by the tax incomes.

4. Transition to protect the pensioners and the elderly. The actual pensioners and elderly will continue to get incomes by the pension on basis of the old program. The workers born after 1938-1953 will take benefits by the new and old system.

By creating a system of notional accounts (in reality there are not deposits on cash means) by linking retirement benefits it will be financed a minimum pension on the collection of general tax revenues. Those born before 1938 will benefit all of the benefits of old pension system. Retirement for those born between 1938-1953 will benefit earnings by a combination between the old system and the new one.

Under the new system the prospective pension for each employee will be based on the amount accumulated on both two separate individual accounts. Most of retirement income although this may change if privatization occurs, will come from the imaginary account held by the government on behalf of the individual. An important part of retirement income, however, will come entirely from the private individual account. The overall rate for contributions is 18.5 per cent, which is slightly under the burden of tax of the old system.

18.5 per cent is divided equally between employers and employees, where everyone pays 9.25 per cent on "basic pension income" in the system. This value is then divided though not uniformly between the maintaining account of the government and the government and private accounts.

\subsection{The imaginary individual account}

From 18.5 per cent of the tax of individual's salary, the majority, 16 per cent of the salary goes to the government program. As is the case of PAYG system the means are used to finance the benefits of current retirees. 16 per cent of the tax for each employee's salary is credited to individual accounts even though the accounts were fictional. These are fictional accounts credited annually with "profits" based on salary growth per capita basis. Starting at the age of 61 a worker can retire, and the government uses monetary fund in this imaginary account to calculate the notional annual benefit for a retired worker. It is important to be stressed that, the calculation is based on life expectancy, the length of stay of an employee at work, the amount of benefit which he/she receives annually. This reform is expected to discourage workers who come to early retirement, which is a common phenomenon.

The table presented below illustrates the pension penalties for workers who come to early retirement, and the bonus they receive when they go to later in retirement.

${ }_{5}^{5}$ IPE investments and pensions Europe 


\begin{tabular}{lc}
\hline Retirement Age & Pension Received $* 6$ \\
61 & $72 \%$ \\
62 & $78 \%$ \\
63 & $84 \%$ \\
64 & $92 \%$ \\
65 & $100 \%$ \\
66 & $109 \%$ \\
67 & $119 \%$ \\
68 & $130 \%$ \\
69 & $143 \%$ \\
70 & $157 \%$ \\
\hline \multicolumn{2}{l}{ Note: *As a \% of normal retirement age (65) pension. }
\end{tabular}

The new pension system will regulate retirement benefits for inflation, though the adjustment will vary depending on real salary growth. This provision creates a direct link between income growth of the work force and tax paid for income, and benefits paid to retirees. This system ensures financial sustainability. But one should not forget the fact that adjustments for inflation may be higher or lower than the rate of inflation depending on whether the real salary growth is higher or lower than 1.6 per cent.

Interesting features of the notional accounts system are:

- As far as the imaginary accounts it will be assigned a modest administrative fee to cover the cost of running the government program.

- The balance of accounts is not transferable to heirs.

- Workforce that leaves to take care of children is credited with contributions from their account.

\subsection{Private Individual accounts}

From 18.5 per cent of the tax and the individual salary event he smallest part 2.5 per cent of the salary goes to private account. This is the financing system part, which means that money is invested in real assets that can be sold to generate income during retirement.

- This system was created to discourage funds with high administrative fees.

- Workers can choose where they want to ensure the provision of income for heirs in case of premature death.

The gradual transition to the new system does not affect individuals born before 1938, and the old system does not affect individuals born after 1953. Persons born between the period 1938 and 1953 profit a mixed benefit as shown in the table below. For example one born in 1948 benefits 70 per cent of the pension benefits in the new systems

\begin{tabular}{lcc} 
Working force years & Percentage of the new pension & Annual pension's amount ${ }^{7}$ \\
1938 & $20 \%$ & $80 \%$ \\
1939 & $25 \%$ & $75 \%$ \\
1940 & $30 \%$ & $70 \%$ \\
1941 & $35 \%$ & $65 \%$ \\
1942 & $40 \%$ & $60 \%$ \\
1943 & $45 \%$ & $55 \%$ \\
1944 & $50 \%$ & $50 \%$ \\
1945 & $55 \%$ & $45 \%$ \\
1946 & $60 \%$ & $40 \%$ \\
1947 & $65 \%$ & $35 \%$ \\
1948 & $70 \%$ & $30 \%$ \\
1949 & $75 \%$ & $25 \%$ \\
1950 & $80 \%$ & $20 \%$ \\
1951 & $85 \%$ & $15 \%$ \\
1952 & $90 \%$ & $10 \%$ \\
1953 & $95 \%$ & $5 \%$ \\
\hline 1954 or later & $100 \%$ & $0 \%$
\end{tabular}

\section{Main Findings and Conclusions}

By filing the problematic situation that our system generates and by the comparison with some of the EU member states it emerges the fact that the reformation scheme is a very good opportunity to bring financial sustainability and the appropriate benefits for the elderly to cope retirement. This is because this scheme currently suffers from a deep deficit and provides benefits covering quite a low and a small number of third ages. Therefore if this scheme is not reformed, the 
benefits will always be lower and some of the citizens will not benefit at retirement. Other motives of reforming the pension scheme are referred as well to the progress of future demographic trends, the data are referred to INSTAT where the fertility rate will drop and this will increase the life expectancy of the third age. World Bank's suggestions are based on the idea of our country's integration with in region and the EU countries. We benefit from European experience in the use of the Open Method of Coordination (OMC) used by these countries to exchange experiences in the field of pensions.

The combination of partial privatization and the PAYG reform part of the retirement pension system will result in the sustainable fiscal system.

Private investment will allow workers to benefit from the rate of return, and will increase the retirement incomes. By reducing the rate of salaries' tax and linking the incomes to the retirement benefits would increase incentives to work. Shifting to a funded system will increase national savings and provide capital for the growth of the future. The first lesson is that countries can switch from a PAYG program into a personal account.

The best option to benefit all individual workers and the entire economy is if the old-age system is partially privatized. In the partial privatization, workers can put 18.5 per cent of their incomes aside for retirement, but they are ready to invest 2.5 per cent of the money in individual accounts. Workers will be able to choose the best fund pension that suits their investment preferences.

The positivity of this system lies in the fact that the return of incomes from imaginary accounts is associated with salary growth per capita, while the returns of private accounts to retirement should reflect long-term return on capital investment. Under the new program, employees may choose to retire at the age of 61 or stay at work until the age of 70 . For attraction brings low benefits at earlier retirement and more incomes when the withdraw later in life, this has no consequences for taxpayers. Workers can continue to work while they benefit an amount of pension. They can choose a partial retirement ( 25 per cent, 50 per cent, or 75 per cent of the amount that they can benefit depending on their age). The future is especially attractive for workers who want withdraw gradually from labor force. They choose a full pension, of course they receive a full pension recalculated in accordance with the age and number of imaginary accounts.

The benefits that this new scheme provides are:

Great incentive to work. In the new pension system the pensions are defined by incomes generated throughout life, which means that at every profiting year the benefits will have a positive impact on the benefits of prospective retirees. Pension rights shall be recorded in real accounts and individual imaginary accounts, workers will have less reason to hide and do not report their incomes. The system will also discourage labor force who leaves the market power.

The increase of national savings and flexible age of retirement will enable non- penalization or non-reward for early retirement. Workers can retire at the age of 61 or can stay in the labor market as they wish. All these positive impacts make it more attractive having an alternate parallel system as the EU member countries.

\section{References}

http://www.sociale.gov.al/dokumenti_i_Pensioneve Alb.pdf

http://www.issh.gov.al/al/

Pension funds in the European debate and within the multilevel decision-making of the European Union. Mariachiara Esposito and David Mum(DWP 2004.02.02)

Latvian pension funds: Multi-Criteria analysis and consumer assessment.Irina Voronova 2011

Revisd taxonomy for pension planes, pension funds and pension entities, Juan Yermo, October 2002

Pension reform in Sweden: Goran Normann and Daniel J. Mitchell. June 29,2000

Pension systems in the EU-contingent liabilities and assets in the public and private sector: Directorate -General for international policies. Economic \& scientific policy, 2011

Notional Accounts as a pension Reform Strategy: An Evaluation, December 1999 Richard Disney

The European Union And Pensions: regulatory intervention, Robin Ellison 2012 